\title{
Low-molecular-weight poly-carboxylate as crystal growth modifier in biomineralization
}

\author{
BALLAV MONI BORAH, BHASKAR JYOTI BHUYAN and GOPAL DAS* \\ Department of Chemistry, Indian Institute of Technology, Guwahati 781039 \\ e-mail: gdas@iitg.ernet.in
}

\begin{abstract}
Construction of modified inorganic mineral with controlled mineralization analogues of those produced by nature is now of current interest for understanding the mechanism of the in vivo biomineralization processes, as well as looking for fresh industrial and technological applications. Lowmolecular-weight chiral poly-carboxylate ligands derived from naturally occurring L- $\alpha$-amino acids have been used as model systems to study the effect of molecular properties on crystal growth modification.
\end{abstract}

Keywords. Biomineralization; growth modifier; amino acid; low-molecular-weight chiral polycarboxylate; calcium mineral.

\section{Introduction}

Biominerals are the bridges between the organic living and the nonliving mineral world. Living organisms form these crystalline minerals. Biominerals are materials such as bones, teeth etc. that perform important functions, and provide robust support and defence (mollusk shell, skeleton) to the individual. They are also used as gravity sensors, for metal storage and for detoxification. ${ }^{1}$ Biominerals are formed by all living organisms, starting from bacteria to higher plants and animals. These minerals are formed in the matrix of bio-macromolecules like proteins, polysaccharides and lipids. Most biominerals are organized hierarchically and are ordered over many length scales starting from nano- to micro-scale. ${ }^{2}$ They often have remarkable physical characteristics. Kinetic control on the nucleation and crystal growth of biominerals morphology is important for functional use.

Biomineralization is the process of mineralization in living system. These materials are deposited in the intra- or extra-cellular matrix. These processes are intimately connected to cellular metabolic processes. Thus, biomineralization as a field of scientific study falls within several branches of basic sciences. ${ }^{3}$ Intimate association of organic and inorganic parts is the hallmark of biomineralization. ${ }^{1,2}$ In many cases, the integration is at the super-structural level, where mineral particles and biopolymers are organized to give composites of unusual strength and

\footnotetext{
*For correspondence
}

toughness. In organisms, several different interconnecting levels regulate the physico-chemical properties of minerals. There is strong inter-relationship between biomineralization and biomimetic material chemistry. ${ }^{4}$ There are fundamentally two different modes of biomineralization. One is called biologically induced mineralization (BIM), in which an organism modifies its local microenvironment creating conditions suitable for the chemical precipitation of extra-cellular mineral phases. The second mode is called boundary-organized biomineralization (BOB), in which inorganic particles are grown within or on some organic matrix produced by organisms. For the last two decades, extensive studies have been done on the biomineralization of calcium minerals. ${ }^{5}$ From these studies it has now been established that biominerals grow on organic templates containing oxygen and nitrogen donor atoms. These structures are stabilized through ion-ion, hydrophobic-hydrophilic interactions etc., which in turn control the structure and morphology of the crystals. Metals like $\mathrm{Ca}^{2+}$ and $\mathrm{Ba}^{2+}$ prefer oxygen donor ligands owing to hard acid-hard base interactions. A study of in vivo $\mathrm{CaCO}_{3}$ biominerals of mollusk shell has revealed the fact that $\mathrm{Ca}^{2+}$ binds to polyanionic sites ${ }^{6}$ of proteins, which change the $\mathrm{CaCO}_{3}$ from the calcite to the aragonite phase. These proteins contain special kind of sequence that mainly contains L-aspartic acid and Lglutamic acid residues. ${ }^{6}$ Depending on the amino acids present at the nucleation centre biominerals grow with different morphologies ${ }^{6}$ that perform various physiological roles. Synthetic biominerals of calcium,${ }^{5 \mathrm{e}}$ barium ${ }^{5 \mathrm{f}}$ and iron $^{4}$ have been prepared. 
Here we report modified, efficient, one-pot syntheses of some low-molecular-weight chiral poly-carboxylate ligands derived form naturally occurring Lamino acids. We also presents the preliminary results of using these chiral poly-carboxylate ligands as templates for crystal growth modifiers in the processes of biomineralization.

\section{Experimental}

\subsection{Materials}

The anhydrous sodium carbonate, anhydrous calcium chloride and sodium sulphate used were analytically pure. The water used in the experiment was the Milli-Q water. All four poly-carboxylate ligands $\mathbf{L}_{1-4}{ }^{7}$ were synthesized modifying the known procedure.

\subsection{Physical measurements}

2.2a Morphological investigations: Optical micrograph images of air-dried samples on glass micro slides were taken using a Zeiss-Axio Cam-MRc microscope fitted with a digital camera. Scanning electron micrograph (SEM) images were obtained by means of a LEO-1430 VP electron microscope on samples glued onto an aluminum stub and gold sputtered.

2.2b FT-IR spectrometry: IR analysis were carried out on air-dried mineral samples. All spectra recorded at $4 \mathrm{~cm}^{-1}$ resolution with 10 scan with a PerkinElmer Spectrum One FT-IR spectrometer from 4000 to $450 \mathrm{~cm}^{-1}$. A background spectrum was measured for pure $\mathrm{KBr}$.

2.2c Powder X-ray diffraction (PXRD) analysis: To confirm the crystalline nature of the mineral sample, PXRD data of air-dried sample were recorded with Seifert powder X-ray diffractometer (XRD 3003TT) with $\mathrm{CuK}_{\alpha}$ source $(\lambda=1.54 \AA)$, on a glass surface.

Table 1. Synthesis of ligands $\mathbf{L}_{\mathbf{1 - 4}}$.

\begin{tabular}{llccc}
\hline $\mathbf{L}$ & $\alpha$-Amino acid & $n$ & Time (h) & Yield $^{\mathrm{a}}(\%)$ \\
\hline $\mathbf{1}$ & L-Alanine & 2 & 5 & 95 \\
$\mathbf{2}$ & L-Phenylalnine & 2 & 6 & 92 \\
$\mathbf{3}$ & L-Aspartic acid & 2 & 8 & 67 \\
$\mathbf{4}$ & L-Lysine & 4 & 10 & 52 \\
\hline
\end{tabular}

${ }^{\text {a Isolated yields }}$ 2.2d Differential scanning calorimetric (DSC) and thermo gravimetric analysis (TGA): In order to determine the presence of organic matrices and water of crystallization in the obtained mineral crystals, the samples were analysed from 25 to $1000^{\circ} \mathrm{C}$ using a DT-40 thermal analyser. Temperature was increased at a rate of $2^{\circ} \mathrm{C} / \mathrm{min}$.

\subsection{Synthesis}

2.3a General synthesis of ligands $\mathbf{L}_{\mathbf{1 - 4}}$ : $\mathrm{N}$-alkylations of amino acids were done by treating them with chloro acetic acid at basic $\mathrm{pH}$ following scheme 1. An aqueous solution of chloro acetic acid was added to the solution of $\mathrm{L}-\alpha$-amino acid in Milli-Q water $(\sim 1 \mathrm{mM})$ in a round-bottomed flask and stirred for $\sim 15$ minutes at RT to make the solution homogeneous. The resulting solution was refluxed. The $\mathrm{pH}$ of the solutions was maintained at $\sim 10 \cdot 0$ for different periods of time (table 1). Different equivalents of chloro acetic acids were added depending on the number of replaceable amine hydrogens present in the amino acids used. The resulting solution was then concentrated to about half of the original volume under reduced pressure. On cooling, a precipitate of $\mathrm{NaCl}$ started forming. The precipitate was filtered and filtrate was acidified with dilute hydrochloric acid and kept overnight for re-crystallization. Crystals were collected by filtration and dried in vacuo.

$2.3 \mathrm{~b} \quad \mathbf{L}_{\mathbf{1}} \quad$ [2-(Bis-carboxymethyl-amino)-propionic acid]: m.p.: $198^{\circ} \mathrm{C}$; ESI-MS, m/z (\%): 205 (86) $\left[\mathbf{L}_{\mathbf{1}}\right]^{+}$; Analysis - Calcd. for $\mathrm{C}_{7} \mathrm{H}_{11} \mathrm{NO}_{6}: \mathrm{C}, 40.98 ; \mathrm{H}$, $5.40 ; \mathrm{N}, 6.83 \%$. Found: C, 41.27; H, 5.96; N 7.14\%; ${ }^{1} \mathrm{H}$ NMR $\left(400 \mathrm{MHz}, \mathrm{D}_{2} \mathrm{O}, 25^{\circ} \mathrm{C}\right.$, TMS $\delta$ (ppm): $1 \cdot 4$ $(d, 3 \mathrm{H}), 3 \cdot 3(s, 4 \mathrm{H}), 3 \cdot 7(q t, 1 \mathrm{H}),{ }^{13} \mathrm{C}$ NMR $(100 \mathrm{MHz}$, $\mathrm{D}_{2} \mathrm{O}, 25^{\circ} \mathrm{C}$, TMS) $\delta$ (ppm): $17 \cdot 4,56 \cdot 2,61 \cdot 4,175 \cdot 2$, $177 \cdot 1$.

$2.3 \mathrm{c} \quad \mathbf{L}_{\mathbf{2}} \quad$ [2-(Bis-carboxymethyl-amino)-3-phenylpropionic acid]: $\quad$ m.p.: $211^{\circ} \mathrm{C}$; ESI-MS, $\mathrm{m} / \mathrm{z}(\%)$ : 281 (92) $\left[\mathbf{L}_{2}\right]^{+}$; Analysis - Calcd. for $\mathrm{C}_{13} \mathrm{H}_{15} \mathrm{NO}_{6}: \mathbf{C}$, $55 \cdot 51 ; \mathrm{H}, 5 \cdot 38$; N, $4.98 \%$. Found: C, 55.82; H, 5.96;

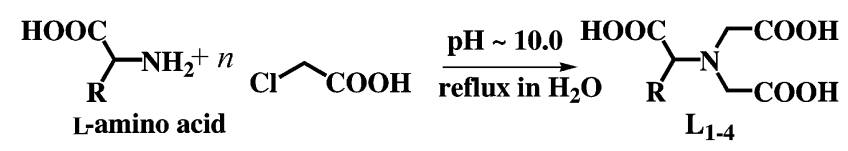

Scheme 1. Synthesis of ligands $\mathbf{L}_{\mathbf{1 - 4}}$. 
N 5.23\%; ${ }^{1} \mathrm{H}$ NMR $\left(400 \mathrm{MHz}, \mathrm{D}_{2} \mathrm{O}, 25^{\circ} \mathrm{C}\right.$, TMS $) \delta$ (ppm): $2 \cdot 9(\mathrm{~m}, 2 \mathrm{H}), 3 \cdot 3(\mathrm{~s}, 4 \mathrm{H}), 4 \cdot 1(t, 1 \mathrm{H}), 7 \cdot 1-7 \cdot 3$ $(m, 5 \mathrm{H}),{ }^{13} \mathrm{C}$ NMR $\left(100 \mathrm{MHz}, \mathrm{D}_{2} \mathrm{O}, 25^{\circ} \mathrm{C}\right.$, TMS $) \delta$ (ppm): 41.7, 56.3, 61.8, 127.4, 129.7, 131.2, 140.9, $179 \cdot 3,184 \cdot 3$.

$2.3 \mathrm{~d} \quad \mathbf{L}_{\mathbf{3}} \quad$ [2-(Bis-carboxymethyl-amino)-succinic acid]: m.p.: $196^{\circ} \mathrm{C}$; ESI-MS, $\mathrm{m} / \mathrm{z}(\%): 249$ (57) $\left[\mathbf{L}_{3}\right]^{+}$; Analysis - Calcd. for $\mathrm{C}_{8} \mathrm{H}_{11} \mathrm{NO}_{8}: \mathrm{C}, 38.56 ; \mathrm{H}$, 4.45; N, 5.62\%. Found: C, 39.07; H, 4.87; N 5.31\%; ${ }^{1} \mathrm{H}$ NMR (400 MHz, $\mathrm{D}_{2} \mathrm{O}, 25^{\circ} \mathrm{C}$, TMS $) \delta$ (ppm): $2 \cdot 6$ $(d, 2 \mathrm{H}), 3 \cdot 5(s, 4 \mathrm{H}), 4 \cdot 0(t, 1 \mathrm{H}),{ }^{13} \mathrm{C}$ NMR $(100 \mathrm{MHz}$, $\mathrm{D}_{2} \mathrm{O}, 25^{\circ} \mathrm{C}$, TMS) $\delta$ (ppm): $34 \cdot 5,58 \cdot 3,61 \cdot 8,179 \cdot 3$, $184 \cdot 3$.

2.3e $\mathbf{L}_{\mathbf{4}}$ [2,6-Bis-(bis-carboxymethyl-amino)-hexanoic acid]: m.p.: $245^{\circ} \mathrm{C}$; ESI-MS, $\mathrm{m} / \mathrm{z}(\%): 378$ (42) $\left[\mathbf{L}_{4}\right]^{+}$; Analysis - Calcd. for $\mathrm{C}_{14} \mathrm{H}_{22} \mathrm{~N}_{2} \mathrm{O}_{10}$ : C, $44.45 ; \mathrm{H}, 5 \cdot 86$; N, 7.40\%. Found: C, 45.11; H, 6.07; $\mathrm{N} 7.21 \% ;{ }^{1} \mathrm{H}$ NMR $\left(400 \mathrm{MHz}, \mathrm{D}_{2} \mathrm{O}, 25^{\circ} \mathrm{C}\right.$, TMS $\delta$ (ppm): $1 \cdot 3(\mathrm{~m}, 2 \mathrm{H}), 1 \cdot 7(\mathrm{~m}, 2 \mathrm{H}), 2 \cdot 1(\mathrm{~m}, 2 \mathrm{H}), 3 \cdot 2(\mathrm{~m}$, $2 \mathrm{H}), 3 \cdot 4(s, 8 \mathrm{H}), 4 \cdot 2(t, 1 \mathrm{H}),{ }^{13} \mathrm{C}$ NMR $(100 \mathrm{MHz}$, $\left.\mathrm{D}_{2} \mathrm{O}, 25^{\circ} \mathrm{C}, \mathrm{TMS}\right) \delta(\mathrm{ppm}): 23 \cdot 2,28 \cdot 5,30 \cdot 2,41 \cdot 4$, $56 \cdot 2,59 \cdot 1,175 \cdot 3,180 \cdot 4$.

2.3f Growing of crystals: The reaction systems were divided into three different groups: Milli-Q water system (control), L-amino acid system (control) and poly-carboxylate ligand system. In a typical experiment, $0.0005 \mathrm{M}$ ligand solution is mixed with $0.001 \mathrm{M} \mathrm{CaCl}_{2}$ solution in Milli-Q water and kept at RT for $12 \mathrm{~h}$ without stirring. Then $0.001 \mathrm{M}$ $\mathrm{Na}_{2} \mathrm{CO}_{3}$ or $\mathrm{Na}_{2} \mathrm{SO}_{4}$ solution is added slowly without much mechanical disturbance. The solution is kept at $25 \pm 2{ }^{\circ} \mathrm{C}$ for several days without any mechanical disturbance. When there are a large number of crystals present in the reaction vessel, the crystalline products are collected, vacuum-filtered and washed with Milli-Q water several times to remove the organic additives, and then finally washed with anhydrous ethanol. The crystals are air-dried and kept in a desiccator for $24 \mathrm{~h}$ before analysis.

\section{Results and discussion}

An in vitro study of biomineralization provides useful information for the design of organic templates. Model systems, in which low-molecular-weight organic additives are used to study the effect of crystal growth modification on inorganic mineralization, provide useful insights into the possible mechanisms operating in nature. Since the proteins that have been found to be associated with biomineralization are usually highly acidic macromolecules, simple water soluble chiral poly-carboxylate ligands were examined as models of biomineralization in aqueous solution.

The following sections describe our recent research on crystal nucleation and growth of calcium carbonate and calcium sulphate in aqueous solution using low-molecular-weight poly-carboxylate ligands.

\subsection{Crystallization of calcium carbonate}

$\mathrm{CaCO}_{3}$ crystal formation in the solution can be observed as an increase in the turbidity of the solution with time. Crystallization of $\mathrm{CaCO}_{3}$ in the presence of $\mathbf{L}_{\mathbf{4}}$ ligand with five pendant carboxylic acid groups resulted in the formation of $\mathrm{CaCO}_{3}$ crystals of perfect octahedron shape (figures 1 and 2) after 5 days. Time-dependent formation of $\mathrm{CaCO}_{3}$ crystals shows that each octahedron is formed by four parts of equal shape. Each part is $200 \mu \mathrm{m}$ in length. In the presence of the low-molecular-weight organic addi-
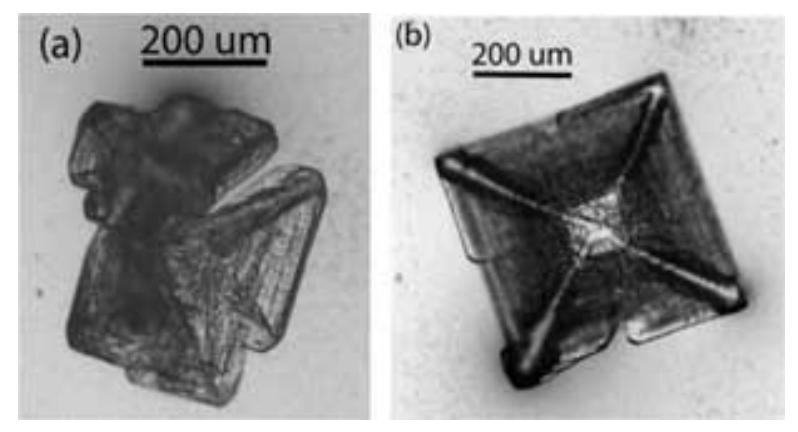

Figure 1. Optical micrograph images of $\mathrm{CaCO}_{3}$ in presence of $\mathbf{L}_{\mathbf{4}}$ : (a) after 2 days and (b) after 5 days.

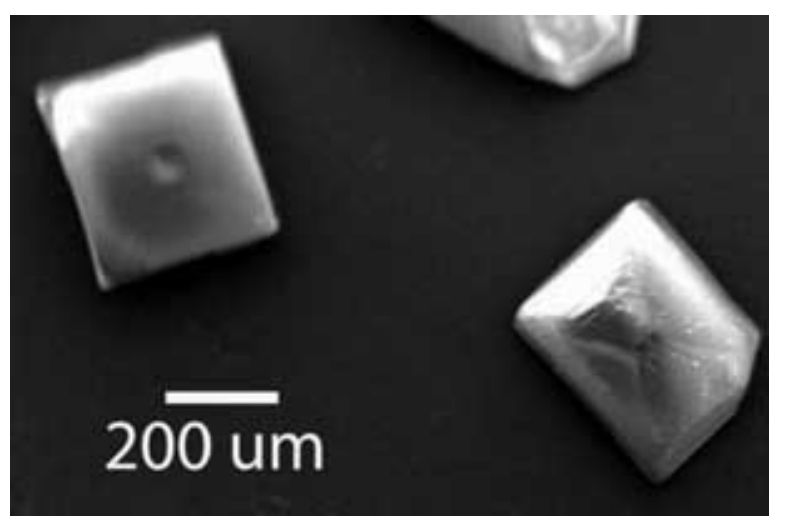

Figure 2. SEM image of $\mathrm{CaCO}_{3}$ in $\mathbf{L}_{\mathbf{4}}$. 
tive, further washing of the crystals with water did not change crystal morphology.

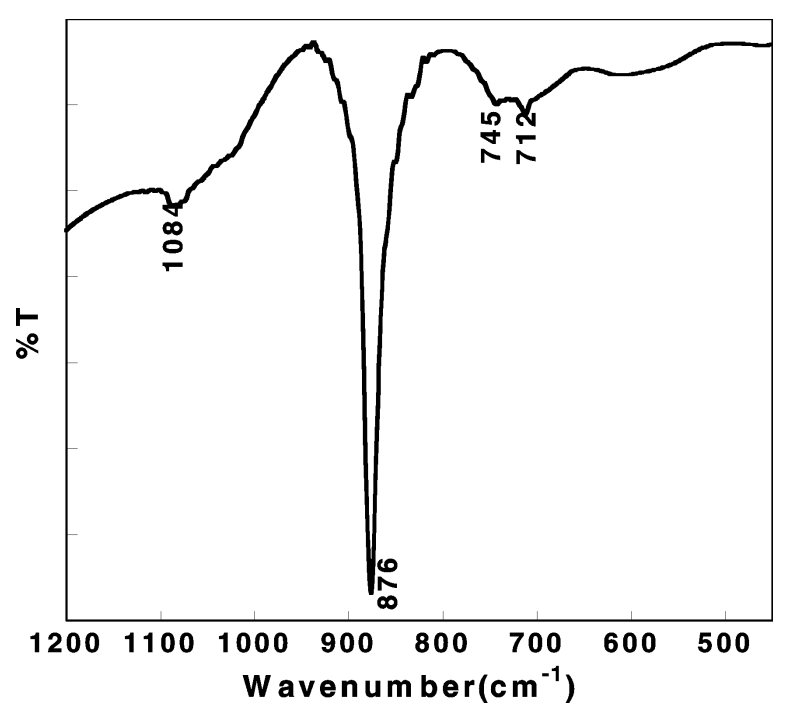

Figure 3. FT-IR spectrum of $\mathrm{CaCO}_{3}$ crystals.

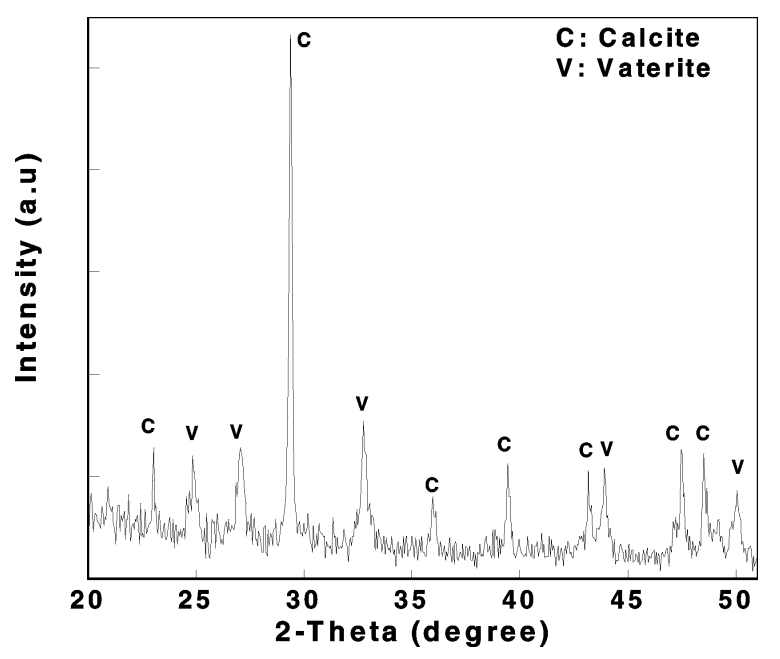

Figure 4. Powder X-ray diffraction pattern of $\mathrm{CaCO}_{3}$ crystals.
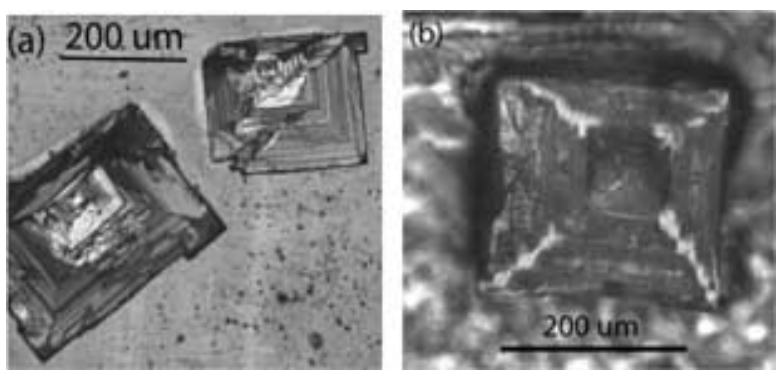

Figure 5. Optical micrograph images of $\mathrm{CaCO}_{3}$ in presence of $\mathbf{L}_{\mathbf{3}}$ : (a) after 2 days and (b) after 5 days.
The precipitation of $\mathrm{CaCO}_{3}$ in the presence of simple L-lysine was also carried out under the same conditions as the control. In this case, spherical crystalline $\mathrm{CaCO}_{3}$ is formed similar to that reported earlier. ${ }^{5 \mathrm{~b}}$ TGA analysis shows the loss of one molecule of $\mathrm{CO}_{2}$ at $750^{\circ} \mathrm{C}$ and DSC analysis shows an endothermic peak centred around $750^{\circ} \mathrm{C}$ corresponding to the removal of one mole of $\mathrm{CO}_{2}$. FT-IR spectra of $\mathrm{CaCO}_{3}$ crystals show the presence of absorption peaks at 1084, 876, 745 and $712 \mathrm{~cm}^{-1}$ (figure 3). These peaks show the co-existence of both the calcite and vaterite phases in $\mathrm{CaCO}_{3}$ crystals. This observation was reinforced by powder XRD data. The powder XRD pattern (figure 4) shows the diffraction peaks from the calcite as well as the vaterite phase. The assignment of polymorphs to calcite or vaterite was carried out by comparison of the literature data with their XRD patterns. Absolute contents of calcite and vaterite in the $\mathrm{CaCO}_{3}$ crystals are 80 and $20 \%$ respectively.

Addition of ligand $\mathbf{L}_{\mathbf{3}}$ derived from L-aspartic acid, the prompted formation of plate type crystals (figure 5). These plates also stacked to give octahedron structure with time. Each side of the octahedron is $200 \mu \mathrm{m}$ in length. The crystal phase is also shown to be calcite $(55 \%)$ along with vaterite $(45 \%)$, as confirmed by FT-IR and powder XRD patterns.

In contrast to the above observations, the ligands $\mathbf{L}_{1-2}$ derived from non-polar amino acids does not show any modification in crystal growth. $\mathbf{L}_{\mathbf{1}}$ shows the formation of bulk precipitate of amorphous $\mathrm{CaCO}_{3}$ without any definite structure (figure 6).

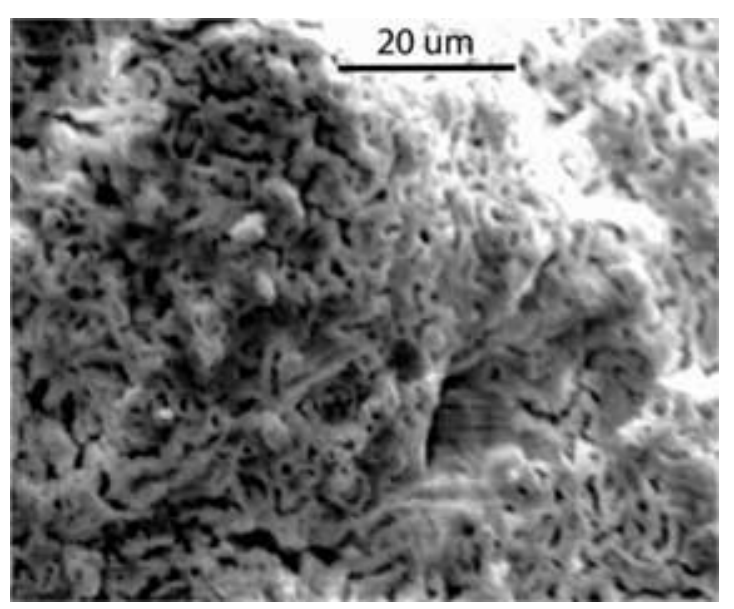

Figure 6. SEM image of precipitated $\mathrm{CaCO}_{3}$ in presence of ligand $\mathbf{L}_{\mathbf{1}}$. 


\subsection{Crystallization of calcium sulphate}

Similar crystal growth modification is followed for the formation of $\mathrm{CaSO}_{4}$ crystals.
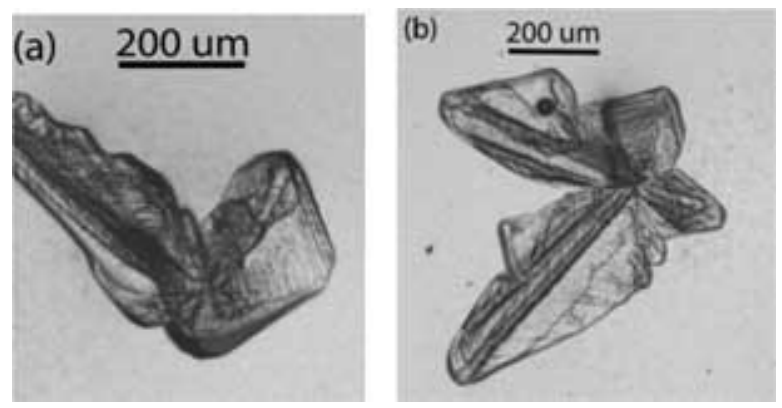

Figure 7. Optical micrograph images of Gypsum in presence of $\mathbf{L}_{\mathbf{4}}$ : (a) after 3 days and (b) after 7 days.

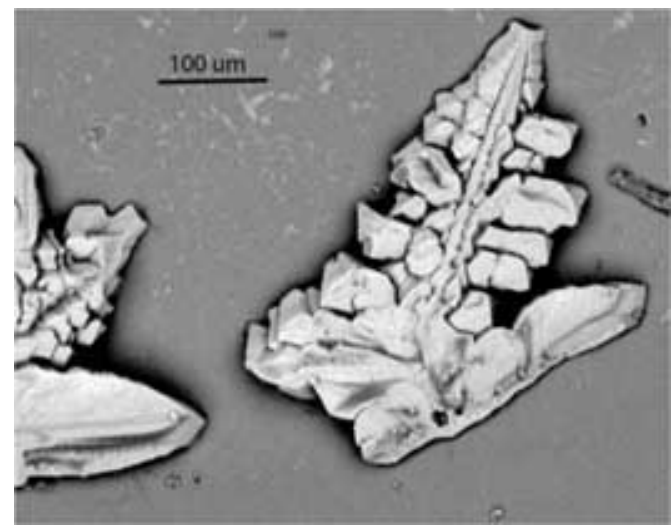

Figure 8. SEM images of gypsum in presence of $\mathbf{L}_{\mathbf{4}}$ after 15 days.

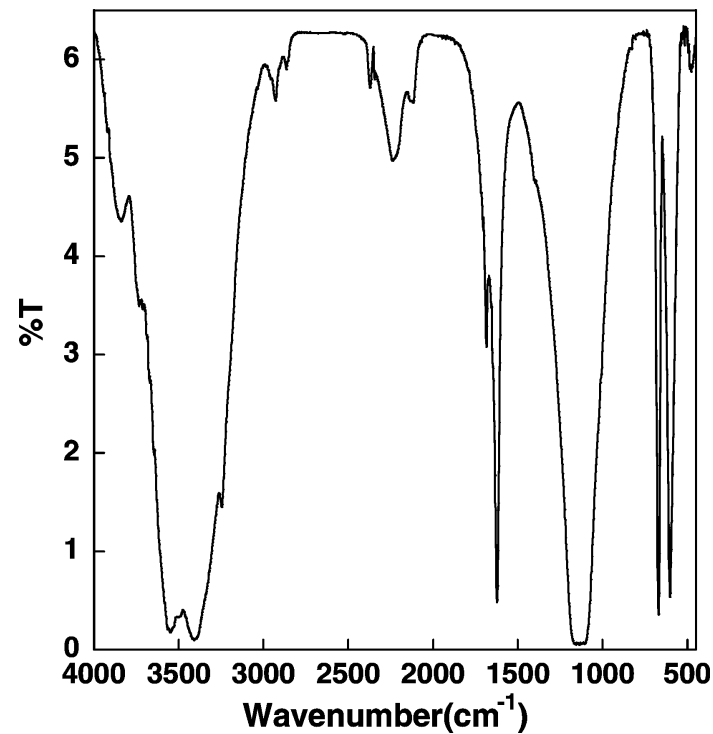

Figure 9. FT-IR spectrum of gypsum formed in the presence of $\mathbf{L}_{\mathbf{4}}$.

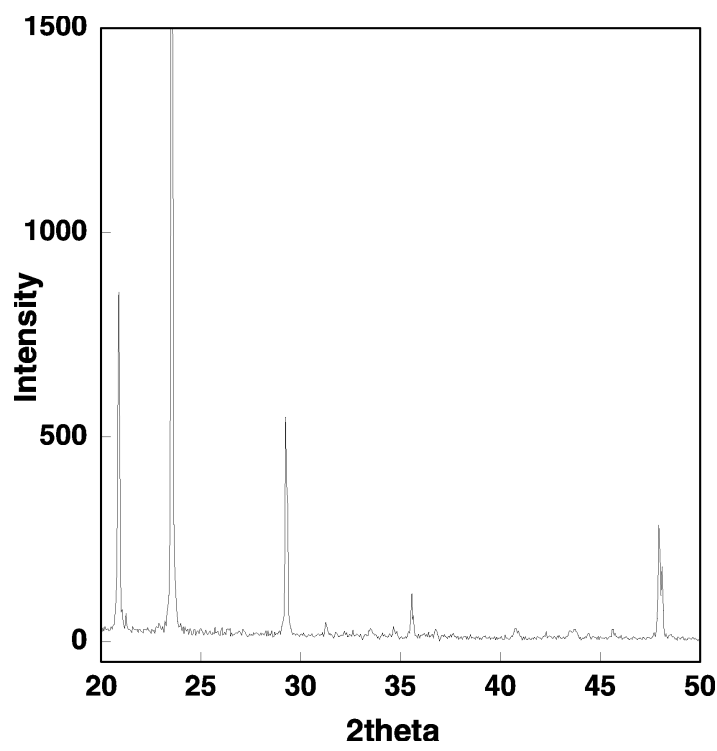

Figure 10. PXRD analysis of gypsum formed in the presence of $\mathbf{L}_{\mathbf{4}}$.

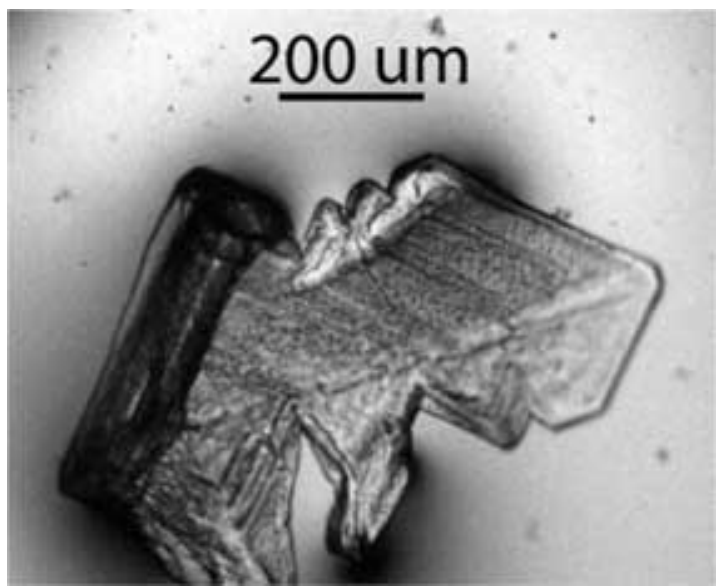

Figure 11. Optical micrograph images of gypsum in presence of $\mathbf{L}_{\mathbf{3}}$ after 10 days.

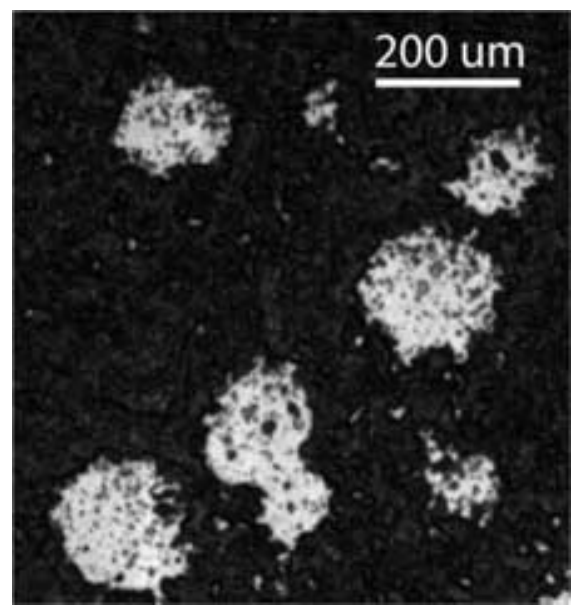

Figure 12. Optical micrograph images of amorphous $\mathrm{CaSO}_{4}$ in presence of ligand $\mathbf{L}_{\mathbf{1}}$. 
In the presence of ligand $\mathbf{L}_{\mathbf{4}}$ it forms leaf like structures (figure 7). Time-dependent studies show the formation of leaf structures with stacked plates of varying length $(200-600 \mu \mathrm{m})$. Matured crystals show the formation of solid leaf structures (figure 8). The crystal phase of the obtained $\mathrm{CaSO}_{4}$ was pure gypsum $\left(\mathrm{CaSO}_{4} \cdot 2 \mathrm{H}_{2} \mathrm{O}\right)$, confirmed by FT-IR (figure 9) and powder X-ray diffraction patterns (figure 10).

TGA analysis shows the loss of two water molecules at $150^{\circ} \mathrm{C}$ and DSC analysis shows an endothermic peak centred around $150^{\circ} \mathrm{C}$ corresponding to the removal of two water molecules.

In the presence of ligand $\mathbf{L}_{3}$, it forms the non-uniform broken leaf structures (figure 11). These nonuniform leaf structures are formed by stacking the plate crystals even after sufficient growing time. The crystal phase is also confirmed to be gypsum in this case.

Once again, in the case of $\mathrm{CaSO}_{4}$ formation both the ligands $\mathbf{L}_{\mathbf{1 - 2}}$ show the same trends as in the case of $\mathrm{CaCO}_{3}$ formation. These ligands show no significant changes in the shape of $\mathrm{CaSO}_{4}$ crystals. $\mathbf{L}_{\mathbf{1}}$ forms agglomerated bulk amorphous precipitate with no uniformity in structure (figure 12).

\section{Conclusion}

Poly-carboxylate chiral ligands of low-molecularweight derived form naturally occurring $\mathrm{L}-\alpha$-amino acids influence the growth of the minerals. A preliminary study of these poly-acidic ligands as matrices in the crystallization of minerals has been tested. Ligand $\mathbf{L}_{\mathbf{4}}$, derived from L-lysine, bearing five pendant carboxylic acid groups proved to be the best matrix for the crystal growth modifier among these four ligands. Non-polar side chains containing amino acid derivatives are not good matrices for mineralization processes.

\section{Acknowledgement}

We gratefully acknowledge the financial support received from the Council of Scientific and Industrial Research, New Delhi. We thank Prof A Chattopadhya for the optical microscope facility.

\section{References}

1. (a) Steed J W and Atwood J L 2000 Supramolecular chemistry (New York: John Wiley \& Sons) pp 450454; (b) Mann S 1996 Biomimetic materials chemistry (Weinheim: VCH) pp 1-39; (c) Frédéric M and Gilles L 2004 C. R. Palevol 3469

2. (a) Mann S 1993 Nature (London) 365 499; (b) Mann S 1988 Nature (London) 332119

3. Baeuerlein E 2000 Biomineralization (Wiley-VCH) pp vii-viii

4. Niemeyer C M and Mirkin C A 2004 Nanobiotechnology (Wiley-VCH) pp 278-287

5. (a) Volkmer D, Fricke M, Huber T and Sewald N 2004 Chem. Commun. 1872; (b) Xiea A-J, Shena Y-H, Zhangb C-Y, Yuanb Z-W, Zhub X-M and Yangb Y-M 2005 J. Cryst. Growth 285 436; (c) Mukkamala S B, Anson C E and Powell A K 2006 J. Inorg. Biochem. 100 1128; (d) Donners J, Heywood B R, Meijer E W, Nolte R J M, Roman C, Schenning A P H J and Sommerdijk N A J M 2000 Chem. Commun. 1937; (e) Yu J, Wei X W, Sun J, Ni Y H, Zhao G C and Ye Y 2004 Chem. Lett. 33 1384; (f) Yu J, Yu J M, Zhang L and Wu L 2004 Chem. Commun. 2414

6. Abmann S E, Viertelhaus M, Heiß A, Hoetzer K A and Felsche J 2002 J. Inorg. Biochem. 91481

7. (a) Svedaite I, Cekuoliene L and Kazlauskas D, 1983 Lietuvos TSR Mokslu Akademijos Darbai B4 59; (b) Hideyuki K, Taiju M, Tomohiro O, Koichiro J, Hisahiko E and Hideki M 2001 Bull. Chem. Soc. Jpn 74 1035; (c) Makoto S, Toru Y and Sumio I 1998 Jpn. Kokai Tokkyo Koho 16; (d) Tercero-Moreno J M, Matilla A, Moreno C F, Gonzalez S and Niclos J 1995 J. Coord. Chem. 35 73; (e) Matilla H A, Gonzalez G S, Tercero Moreno J M, Candida M, Vaz T A and Vilas B L 1987 Talanta 34519 